\title{
A two-stage production planning model for perishable products under uncertainty
}

\author{
Hamid Reza Hosseini Jey ${ }^{a^{*}}$, Hassan Javanshir ${ }^{\mathrm{b}}$ and Amir Mohajeri ${ }^{\mathrm{a}}$
}

${ }^{a}$ Department of Industrial Engineering, Central Tehran Branch, Islamic Azad University, Tehran, Iran ${ }^{b}$ Department of of Industrial Engineering, South Tehran Branch, Islamic Azad University, Tehran, Iran

\begin{tabular}{l}
\hline C H R O N I C L E \\
\hline Article history: \\
Received July 2, 2016 \\
Received in revised format \\
September 10, 2016 \\
Accepted January 92017 \\
Available online \\
January 92017 \\
\hline Keywords: \\
Production Planning \\
Manual production \\
Automatic production \\
Non-linear programming \\
Human force \\
Production machineries \\
Products'spoilage
\end{tabular}

\section{Introduction}

Determining the optimal production model for perishable products and optimal sales prices for these products has always been one of the main topics among academics and industrial researches (Mahmoodi et al., 2014). Deterioration is something that, over time occurs on many products in the real-world and imposes some additional costs on production system. Many types of foods, pharmaceutical and chemical materials, blood and so on are perishable products. In fact, deterioration refers to types of injury, waste, drying or evaporation (Banerjee \& Turner, 2012). This means that the product deviates from its expected performance. According to the importance of the value of the optimal production of these types of products and according to the life-limited distribution and sale systems in perishable products and the high costs due to maintaining inventory and production of such products, many studies have been carried out. In this paper, we try to improve a model to optimize the

* Corresponding author Tel.: +989124056948

E-mail address: hamidelisha@yahoo.com (H. R. Hosseini Jey)

(C) 2017 Growing Science Ltd. All rights reserved.

doi: $10.5267 / j . u s c m .2017 .1 .002$ 
production planning of these types of products when there is uncertainty in demand (Shah \& Ierapetritou, 2012).

\subsection{Literature review}

Supply chains for perishable items consist of products with a fixed shelf life and limited production/collection; managing them requires competent decision-making (Katsaliaki et al., 2014). Risk is inherent in many economic activities especially for production activities where results of decisions made today may have different outcomes depending on future events (Mirzapour Al-eHashem et al., 2012). Ji et al. (2016) investigated the optimal production planning for an assembly system with $n$ components in a single period setting by considering uncertainty in Demand for the endproduct, production and assembly capacities.

Chen and Xiao (2015) studied the backup sourcing strategy of the buyer and the production planning of the supplier and analyzed the value of backup sourcing for both the decentralized and centralized channels. Feng et al. (2015) studied a joint pricing and dynamic production policy for perishable goods without considering shortages. They proposed a dynamic optimization model to maximize total profit by assigning a limited production capacity and setting a suitable sales price. Pauls-Worm et al. (2015) performed an investigation on the practical decision problem of fresh food production with a long production lead time.

Gupta and Mohanty (2015) introduced a technique to solve a multi-stage production planning problem by considering different objectives, which are conflicting with each other. Gyulai et al. (2015) provided a combined production planning and capacity control method for assembly lines to balance the workload of the human operators and decrease the overall production expenses on a given time horizon. Hees and Reinhart (2015) proposed a changeable and reconfigurable manufacturing systems in a multitude of research publications. They also proposed a prototypical application scenario, for the evaluation of the feasibility of the planning approach. Mirzaei and Seifi (2015) presented a mathematical model for an inventory routing problem for assigning the stock of perishable products and assuming that the age of the perishable inventory maintained a negative effect on the demand of end customers and a portion of the demand was considered as lost sale. Perishable products represent an essential area in the retail industry and our daily lives (Duong et al., 2015).

Sel et al. (2015) considered a dairy industry problem on integrated planning and scheduling of set yoghurt production. They also proposed a mixed integer linear programming formulation to integrate tactical and operational decisions. Aung and Chang (2014) addressed the methods applied to improve the ability to define an optimal target temperature for multi-commodity refrigerated storage. PaulsWorm et al. (2014) studied the practical production planning problem of a food producer encountering an on-stationary erratic demand for a perishable product with a fixed life time. Negon et al. (2014) considered a system with stochastic demand and a single consolidation point near the suppliers. Shirvani et al. (2014) proposed a method for a realistic cyclic scheduling problem in the food industry environment in which parallel machines were considered to process perishable jobs with given release dates, due dates and deadlines.

Bilgen and Çelebi (2013) addressed the production scheduling and distribution planning problem in a yoghurt production line of the multi-product dairy plants. One of the important characteristics of perishable products that a decision-maker has to take into account seriously is that the price will drop significantly after a day, or a season (Leung \& Ng., 2007). Shen (2013) presented a deterministic nonlinear program in rolling-schedule form for multi-item production planning with uncertain demand and a capacity constraint. Farahani et al. (2012) investigated how the quality of some foods could be improved by shortening the time interval between production and delivery. Ahumada and Villalobos (2011) presented an operational model that generates short term planning decisions for the fresh 
produce industry. Mirzapour Al-e-hashem et al. (2011) considered a supply chain including multiple suppliers, multiple manufacturers and multiple customers, addressing a multi-site, multi- period, multiproduct aggregate production planning (APP) problem under uncertainty. Two fundamental processes usually happen in the production planning of different industries. The first one consists of deciding how many final products of each type have to be produced in each period of a planning horizon, the wellknown lot sizing problem. The other process consists of cutting raw materials in stock in order to produce smaller parts used in the assembly of final products, the well- studied cutting stock problem (Gramani et al., 2011). Kazemi Zanjani et al. (2010) addressed a multi-period, multi-product sawmill production planning problem where the yields of processes were random variables because of nonhomogeneous quality of raw materials. Chen et al. (2008) proposed a nonlinear mathematical model to consider production scheduling and vehicle routing with time windows for perishable food products in the same framework. Multi-commodity production and distribution scheduling is one of the most complex and crucial problems facing many manufacturing companies (Christou et al., 2007; Tarantilis \& Kiranoudis, 2001).

\section{Problem statement}

The system investigated here is for a chemicals production factory with 1 production line and 2 manual and automatic technologies. In manual technology, workers are working with 3 amateur, typical and professional skills in 2 typical and overtime working. Automatic technology in this system has $n$ machines in which the repairing and maintenance of the machineries also is included. This system has $n$ products. The products are life-limited and they are various.

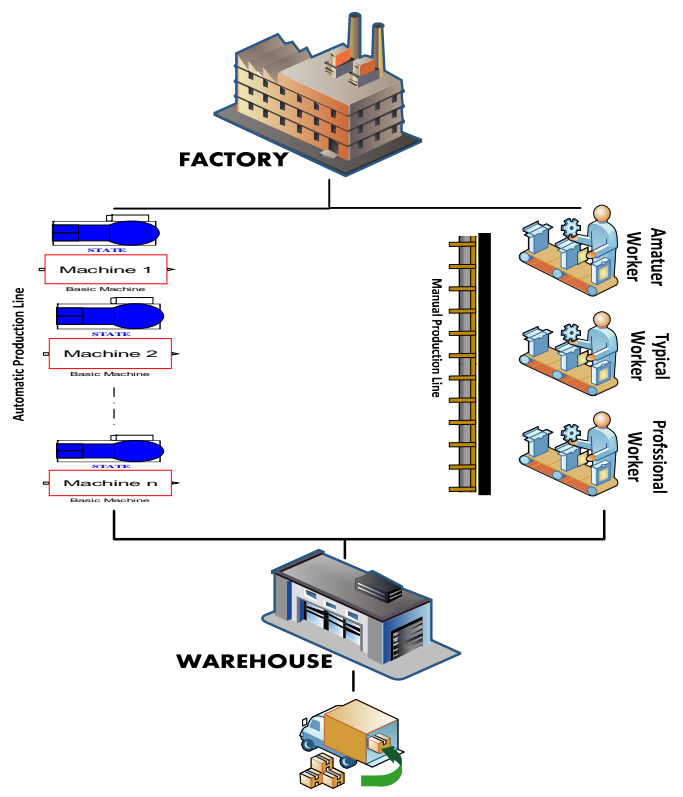

Fig. 1. Manufacturing system

The main goal is to propose a model for improvement of the production planning and minimization of the production system costs. The products in high volume and various types are produced and are stored in bottles as the final products. For different production periods, the human forces capacities are considered and the level of employment or forces dismissal is considered. The production process is forwarding and backward process is not acceptable; that is, it is not allowable to rework in this system. According to the organization management urgent need to reduce production costs of these types of the products, objective function is minimizing costs. Backlog deficiency is allowable in the final stage of production. Product spoilage is allowable in all stages and production capacity and store capacity are considered. Delivering final product from stockpiles to the retailers is conducted using vehicles with limited capacity. 
- $\quad$ Demand is considered to be certain.

- $\quad$ The expiry date of the products are certain and precise.

- $\quad 3$ amateur, typical and professional skills are considered for workers.

\section{Mathematical model}

\section{Indices}

$i$ : Products' index

$t$ : Time index

$k$ : Index of different labor skills $(\mathrm{k}=1,2,3)$

\section{Parameter}

$D_{i t}$ : Predicted demand for the product of group $i$ at time $t$

$C D Q_{i t}$ : Manual production cost at usual time for each unit of the product $i$ per time $t$ (price/unit)

$C A Q_{i t}$ : Automatic production cost at usual time for each unit of the product $i$ per time $t$ (price/unit)

$C A O_{i t}$ : Overtime working automatic production cost for each unit of product $i$ per time $t$ (price/unit)

$C D O_{i t}$ : Overtime working manual production cost for each unit of product $i$ per time $t$ (price/unit)

$C I n v_{i t}$ : Inventory storing costs for each unit of product $i$ per time $t$ (price/unit)

$C B_{i t}$ : Delayed orders costs for each unit of product $i$ per time $t$ (price/unit)

$C H_{t}^{k}$ : Level $K$ labor employment cost per time $t$ (price/hour)

$C L_{t}^{k}$ : Level $K$ labor dismiss cost per time $t$ (price/hour)

$C W_{t}^{k}$ : cost of one worker per time $t$ (typical and overtime working wage per time $t$ ) (price/hour)

$C F_{i t}$ : cost of product $i$ spoilage per time $t$ (price/unit)

$C G_{t}$ : Other costs per time $t$ (price/unit)

$\theta W_{t}$ : Working hours for each worker per time $t$

$\delta$ : Available labor shortage for overtime

$A n_{i t}$ : Time required for producing product $i$ automatically (working hours on each unit of $i$ per time $t$ ) (person-hour/unit)

$D n_{i t}^{k}$ : Time required for producing product $i$ manually (working hours on each unit of $i$ per time $t$ ) (person-hour/unit)

$V_{t}^{\max }$ : Maximum store space per time $t\left(\mathrm{~m}^{2}\right)$

$V_{i t}$ : Occupied space for each unit of product $i$ per time $t$ (price/unit)

$t N_{t}$ : Machineries maintenance and repair time per time $t(t=1,2, \ldots, n)$

$t D^{k}{ }_{i}$ : Time of the producing process of product $i$ by level $k$ labor in manual technology $(i=1,2, \ldots, \mathrm{n})$

$t A_{i}$ : Time of the producing process of product $i$ by level $k$ labor in automatic technology $(i=1,2, \ldots, \mathrm{n})$

$T m_{i}$ : Product spoilage threshold time per each period

$\operatorname{Mmax}_{t}$ : Maximum machineries per each period

$\theta M_{t}$ : Available time for machineries per time $t$

$r_{i t}$ : Automatic production time for product $i$ per time $t$ by machineries

$W_{\text {tmax }}$ : Maximum allowable labor per each period

$\alpha$ : Coefficient of the overall labor employed or dismissed per each period

Cap: Vehicle capacity for product transportation

$\beta$ : Machineries shortage available for overtime working

$w 1$ : weight of production, maintenance, delayed order and product's spoilage costs

w2: labor costs weight

w3: weight of other costs 


\section{Decision Variables}

$D Q_{i t}^{k}$ : Manual production at typical time for product $i$ per time $t$ (unit) by level $k$ workers

$A Q_{i t}$ : Automatic production at typical time for product $i$ per time $t$ (unit)

$A O_{i t}$ : Automatic production at overtime working for product $i$ per time $t$ (unit)

$D O_{i t}^{k}$ : Manual production at overtime working for product $i$ per time $t$ (unit) by level $k$ workers

$I n v_{i t}$ : inventory level for product $i$ per time $t$ (unit)

$B_{i t}$ : Delayed order level for product $i$ per time $t$

$H_{t}^{k}$ : Number of employed level $k$ worker per time $t$ (person/hour)

$L_{t}^{k}$ : Number of dismissed level $k$ worker per time $t$ (person/hour)

$W_{t}^{k}$ : Number of level $k$ workers required per time $t$

$X_{t}$ : Number of vehicle required for products transportation from store to retail

$F_{i t}$ : Number of the spoiled products $i$ per time $t$

$P_{i t}$ : Level of the distributed product $i$ from factory per time $t$

$X$ : Human force employment index

$Y$ : Human force dismiss index

\section{Mathematical model}

Objective function:

Objective function relates to the minimization of typical and overtime working production costs automatically and manually, inventory storage, delayed orders, employment and dismissal of the forces.

$$
\begin{array}{r}
\min z_{=}\left(\sum_{i=1}^{N} \sum_{t=1}^{T}\left\{A Q_{i t} * C A Q_{i t}+A O_{i t} * C A O_{i t}+\sum_{k=1}^{K} D Q_{i t}^{k} * C D Q_{i t}+\sum_{k=1}^{K} D O_{i t}^{k} * C D O_{i t}\right\}+\sum_{i=1}^{N} \sum_{t=1}^{T}\left\{\operatorname{Inv} v_{i t} * C I n v_{i t}+B_{i t}\right.\right. \\
\left.\left.* C B_{i t}\right\}+\sum_{i=1}^{N} \sum_{t=1}^{T}\left\{F_{i t} * C F_{i t}\right\}\right)+\left(\sum_{t=1}^{T} \sum_{k=1}^{K}\left\{w_{t}^{k} * C W_{t}^{k}\right\}+\sum_{t=1}^{T} \sum_{k=1}^{K}\left(H_{t}^{k} * C H_{t}^{k}+L_{t}^{k} * C F_{t}^{k}\right)\right)+\sum_{t=1}^{T} C G_{t}
\end{array}
$$

subject to

$$
\begin{aligned}
& w_{t}^{k}=w_{t-1}^{k}+H_{t}^{k}-L_{t}^{k} \quad \forall t=1, \ldots, T, k=1,2,3 \\
& \sum_{i=1}^{N} D n_{i t}^{k} * D Q_{i t}^{k} \leq \theta w_{t} * w_{t}^{k} \quad \forall t=1, \ldots, T, k=1,2,3 \\
& \sum_{i=1}^{N} D n_{i t}^{k} * D O_{i t}^{k} \leq \delta * \theta w_{t} * w_{t}^{k} \quad \forall t=1, \ldots, T, k=1,2,3 \\
& H_{t}^{k}+L_{t}^{k} \leq \alpha * w_{t}^{k} \quad \forall t=1, \ldots, T, k=1,2,3 \\
& B_{i t}=D_{i t}-P_{i t} \\
& \operatorname{In} v_{i t}=\sum_{k=1}^{K} D Q_{i t}^{k}+\sum_{k=1}^{K} D O_{i t}^{k}+A Q_{i t}+A O_{i t}-P_{i t}+\operatorname{In} v_{i t-1} \\
& \sum_{k=1}^{K} w_{t}^{k} \leq \text { Wmax }_{t} \quad \forall t=1, \ldots, T \\
& \sum_{i=1}^{N} r_{i t} * A O_{i t} \leq \beta * \operatorname{Mmax}_{t} \\
& \sum_{i=1}^{N} r_{i t} * A Q_{i t} \leq \operatorname{Mmax}_{t} \\
& \sum_{i=1}^{n} V_{i t} * \operatorname{Inv}_{i t} \leq \operatorname{Vmax}_{t} \quad \forall t=1, \ldots, T \\
& \left(\sum_{k=1}^{K} t D^{k}{ }_{i} \cdot D Q_{i t}^{k}+\sum_{k=1}^{K} t D^{k}{ }_{i} D O_{i t}^{k}\right)+t A_{t}\left(A Q_{i t}+A O_{i t}\right)+t N_{t} \geq T m_{i} \times X_{i t} \\
& \forall t=1, \ldots, T, i=1, \ldots, N \\
& \left(\sum_{k=1}^{K} t D^{k}{ }_{i} \cdot D Q_{i t}^{k}+\sum_{k=1}^{K} t D^{k}{ }_{i} D O_{i t}^{k}\right)+t A_{t}\left(A Q_{i t}+A O_{i t}\right)+t N_{t} \leq X_{i t} \times M+T m_{i} \\
& \sum_{i=1}^{n} X_{i t}=F_{t} \\
& \sum_{i=1}^{N} P_{i t} \leq \text { Cap } * X_{t} \quad \forall t=1, \ldots, T \\
& W_{t}, H_{t}, L_{t} \geq 0 \\
& D O_{i t}^{k}, D Q_{i t}^{k}, A Q_{i t}, A O_{i t}, X_{t} \geq 0 \\
& \mathrm{Xit}=0,1
\end{aligned}
$$

Constraint (1) relates to labor balance equation. Labor per each period is the number of forces in previous period plus employed forces minus dismissed ones. Constraints (2) and (3) state that sum of the manual production in typical and overtime working must not exceed the allowable working hours for production in overtime and typical working. Constraint (4) states that employment and dismissal level per each period must not exceed a percent of the labors at that time. Constraint (5): level of delayed 
order in each period with the demand per each period distributed from the factory. Constraint (6): inventory level per each period equal to level of products in this period minus distributed level in this period plus inventory in previous period. Constraint (7) relates to the allowable labor per each period. Constraints 8 and 9 are related to the allowable time available for machineries. Constraint (10) is the storage space. Constraints (11) and (12) are products spoilage which states that production time and product storage should not exceed a given level and $X_{i t}$ which is a 0 and 1 variable, indicates the spoiling products number index. Constraint (13) stated that sum of spoiling products is equal to sum of all spoiled products in certain period. Constraint (14) is the capacity of vehicles for transportation to retailers. Finally, Constraints (15), (16) and (17) indicate the variables of problem.

\section{The proposed Genetic Algorithm}

We proceed to solve the model by Genetic Algorithm. The following shows the implementation of this method.

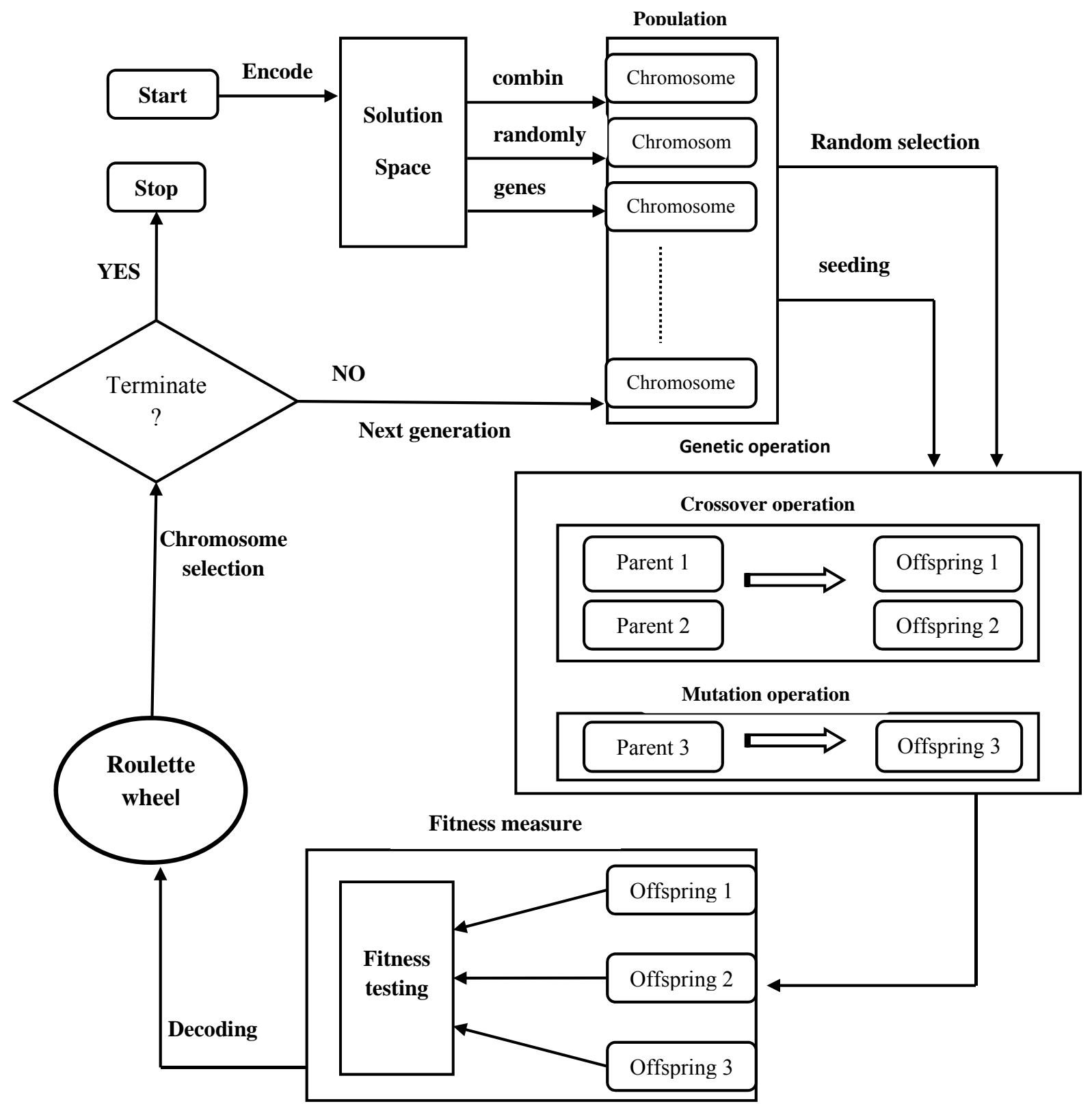

Fig. 2. The structure of the proposed genetic algorithm 
Then we proceed to evaluate the performance of the model solution in different dimensions with Genetic Algorithms and Gams.

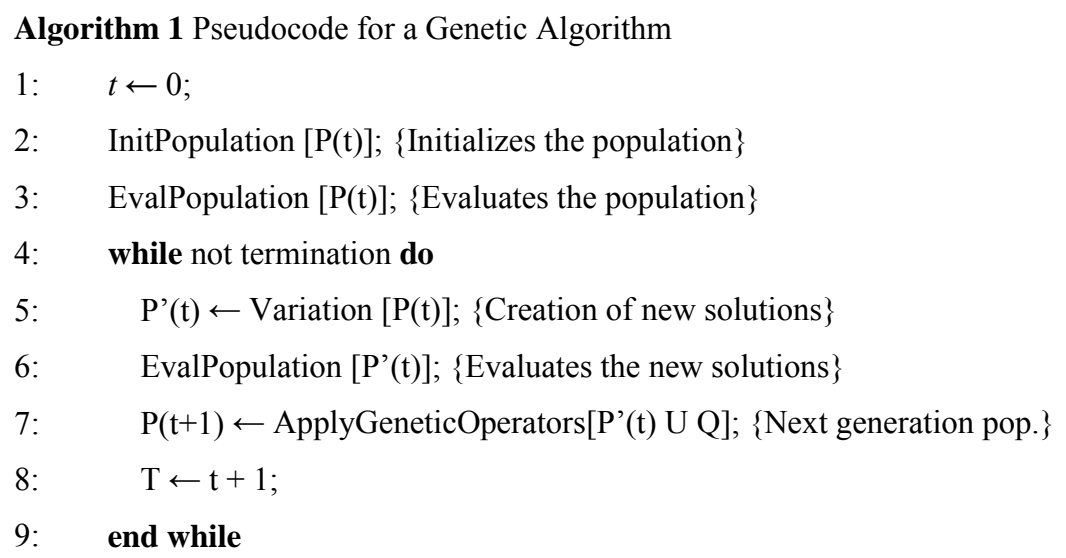

\section{Creating an initial population}

After determining the coding system and specifying the methods of converting each answer to chromosome, the initial population of chromosome must be generated. In most cases, the initial population is generated, randomly. But sometimes for enhancing the speed and quality of the algorithm, innovative methods are used to generate the initial population. Nevertheless, use of a random approach is the most common and the easiest way. Dimension of initial population usually depends on the size of the coded field. For example, if the chromosomes are in a 32-bit issue, selective population of chromosomes should definitely be greater than, for example, 16-bit.

The probability of cutting is between 80 to 95 percent, the probability of mutation is between half to one percent and population size is between 20 and 30. Then according to a fitness function, we allocate a real value to the selected chromosomes that represents their values and the process of Genetic Algorithms continues. If the number of chromosomes becomes too small, the Genetic Algorithm will have less possibility to combination action and only a small portion of the search space will be discovered. On the other hand, if the number of chromosomes becomes too populous, the Genetic Algorithm process will be slow, survey has shown that due to some limitations, which depends mainly on encoding and the issue, we use of a large population.

\subsection{Encoding}

This is perhaps the most difficult phase of the problem. One way of encoding is binary encoding, where its aim is conversion the answer of problem to a string of binary numbers (in base 2).

\begin{tabular}{|l|l|l|l|l|l|l|l|l|l|}
$\mathrm{a}$ & $\mathrm{b}$ & $\mathrm{c}$ & $\mathrm{d}$ & $\mathrm{e}$ & $\mathrm{f}$ & & \multicolumn{1}{c}{$\cdots$} \\
\hline 0 & 1 & 0 & 1 & 0 & 1 & 0 & 1 & 0 & 1 \\
\hline
\end{tabular}

Encoding structure of chromosome in the N-GA

\subsection{Population}

The concept of population in Genetic Algorithm is similar to what happens in normal life. In the Genetic Algorithm as the first stage it is necessary to create a set of possible answers as the initial population. These members are usually chosen randomly but in optimization algorithms, constraints are used until the population does not have inordinate distribution. The number of members of the population depends on the type of problem. Indeed, the number of members is a parameter that by changing can improve 
accuracy of the solution and the speed of convergence search. In some problems, a population of 8 members is completely suitable, while a population of 100 members is not enough in other cases. Based on the experience, it is better that the number of members is considered between 10 and 160 .

\subsection{The initial population creation}

After determining the encoding system and determine the methods of converting each answer to chromosome, the primitive population of chromosome must be produced. In most cases, the initial population is generated randomly. But sometimes innovative methods are used for enhancing the speed and quality of the algorithm to generate the initial population. The use of a random approach is the most common and the easiest way. The initial population usually depends on the size of the encoded string. For example, if the chromosomes are in a 32-bit issue, selective population of chromosomes should definitely be greater than the, for example, 16-bit. Usually, the probability of cutting is between 80 and 95 percent, the probability of mutation is between half to one percent and population size is from 20 to 30. Then according to a fitness function, we allocate a real value to the selected chromosomes that represents their values and the process of Genetic Algorithms continues.

\subsection{Population size}

The following is used to calculated the size of the population,

$N_{\text {Pop }}=1.65 \times 2^{(0.21 \times L c)}$

For example, if the length of each chromosome is equal to 25 , then we get: $N_{P o p}=1.65 \times 2^{(0.21 \times 25)}=62$. If the number of chromosomes is chosen too small, the Genetic Algorithm will have less possibility for combination action and only a small portion of the search space will be discovered. On the other hand, if the number of chromosomes is too populous, the Genetic Algorithm process will become slow, survey has shown that due to some restrictions, which depends mainly on encoding and the issue, the use of a large population will not be effective.

\subsection{Roulette wheel selection}

Fitness proportionate selection, also known as roulette wheel selection, is a genetic operator implemented in genetic algorithms for choosing potentially useful solutions for recombination. If $f_{i}$ is the fitness of individual $i$ in the population, its probability of being selected is

$$
P_{k}=\frac{f_{k}}{\sum_{i=1}^{n} f_{i}},
$$

where $n$ is the number of individuals in the population.

\subsection{Steady State Selection}

In most genetic algorithms which have been proposed in the literatures, a new population is created entirely by children. In some ways some of the older members of the population have permission to attend the new population. Steady State Selection is one of these methods.

\subsection{Elitism Selection}

The idea of Elitism adds new features to choice process. In the elitism, the best member of the population survives, and will present in the population. In other words, a member that has the highest correlation, is automatically transferred to the new population.

\subsection{Rivalry selection}

This method selects the number of members of the population randomly and then if certain conditions are met, the best is select as parent, if the condition is not established, the worst or some of the worst, 
in the formation of future population are considered as parents. The standard form of this model is dual competition or binary and it is as follows:

1. 2 members are selected randomly.

2. $r$ is determined between 0 and 1 , randomly.

3. The parameters $1 \geq \mathrm{K} \geq 0$ is set by the user. (e.g. $\mathrm{K}=0.75$ )

4. If $k>r$ is the top member and if $r \leq K$ is the worst member, a parent is selected between two members.

5. Two members are selected for the competition, returned to the population and can participate in the competition again. Competitive selection method can also be performed for each competition with $n$ persons.

\subsection{Brindle unconditional selection}

The method presented and introduced by "Brindle", is the probability of selection for each chromosome which is calculated as follows,

$P_{k}=\frac{f_{k}}{\sum f_{i}}$

and the expected number for each chromosome is derived as follows,

$e_{k}=P_{k} .($ Pop_Size $)$.

\subsection{Uniform Crossover}

The most important operator of genetic algorithm is crossover operator. Crossover is a process that the older generation in chromosomes are uniformed together and crossover to create a new generation of chromosomes.

\subsection{Mutation}

In the nature, some factors such as ultraviolet radiation may create unpredictable changes in chromosomes. Since genetic algorithms follow the law of development, the mutation operator is applied with a low probability. Mutation makes search in intact spaces, it can be deduced that the most important task of mutation is avoid to the convergence to local optimum. For the proposed study of this paper, the following shows the mutation operation.

\begin{tabular}{|l|l|l|l|l|l|}
\hline 1 & 1 & 0 & 0 & 1 & 0 \\
\hline
\end{tabular}

As noted earlier, each member, depending on the mutation probability, would be mutated. Mutation probability $P_{m}$ is a value that is set by the user.

\subsection{Genetic Algorithm parameter tuning}

One of the important points in designing a Genetic Algorithm is the regulation of its parameters. Regulation of the parameters chooses the best values for parameters so that the algorithm performs well. Here we use Minitab software outputs to locate the optimal values for each parameter. The most important parameters of Genetic Algorithm as follows, 
- Population size and the number of repeat

- Probability of the crossover

- Probability of the mutation

In this research Taguchi method is used for parameter regulation. Orthogonal array is an interaction between two basic concepts and the signal to noise $\operatorname{ratio}(\mathrm{S} / \mathrm{N})$. Orthogonal array (OA) was a method presented by Taguchi to achieve the minimum number of possible tests that only considers a fraction of all factorial combinations. The signal to noise ratio in the Taguchi method, is used as a target in efficiency and represents the product or process consistency. This issue is solved in two steps:

(a) Maximizing the signal to noise ratio,

(b) Regulate mean of the process by using control factors.

Different criteria as signal to noise ratio was proposed by Taguchi where the most important of them are as follows,

- The larger the better (LTB)

- The smaller the better (STB)

- The nominal the best (NTB)

According to the objective function of this research, the smaller the better is used. Relation of signal to noise ratio in this criterion is:

$\mathrm{S} / \mathrm{N}$ Ratio $(\mathrm{y})=-10 \log 10\left(\frac{\left(\sum y^{2}\right)}{n}\right)$

The signal to noise ratio usually is measured by decibel $(\mathrm{dB})$ unit. The higher value indicates the higher quality of the process. For the analysis of optimal values of the parameters in Taguchi, we use 5 levels given in Table 1 and Fig. 2 and Fig. 3 present the details of Taguchi method. Also, Table 2 presents the results of optimal parameters.

\section{Table 1}

Factors and their levels in parameter regulation Taguchi

\begin{tabular}{lccccc}
\hline Parameter & Level 1 & Level 2 & Level 3 & Level 4 & Level 5 \\
\hline Population size and number of repeat & $(10,50)$ & $(20,70)$ & $(50,100)$ & $(40,140)$ & $(60,180)$ \\
Probability of crossover & 0.6 & 0.7 & 0.8 & 0.9 & 0.8 \\
Probability of mutation & 004 & 0.06 & 0.02 & 0.03 & 0.09 \\
\hline
\end{tabular}

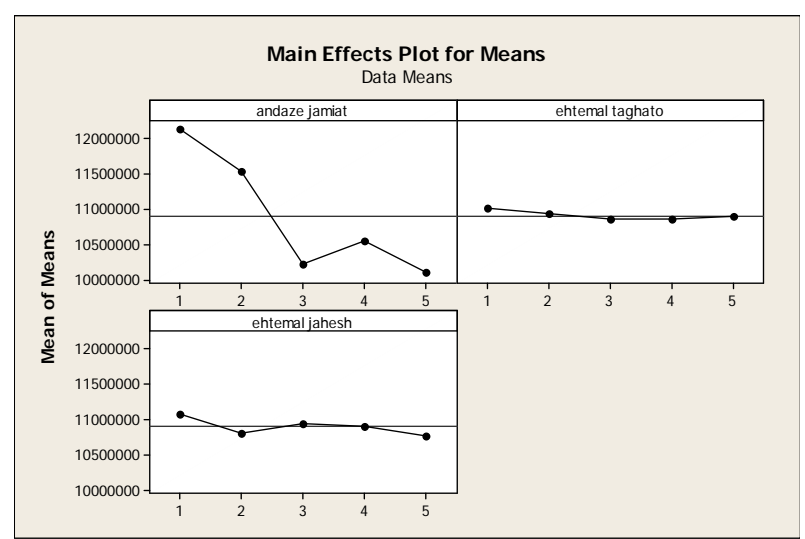

Fig. 3. The results of the main effects plot for mean

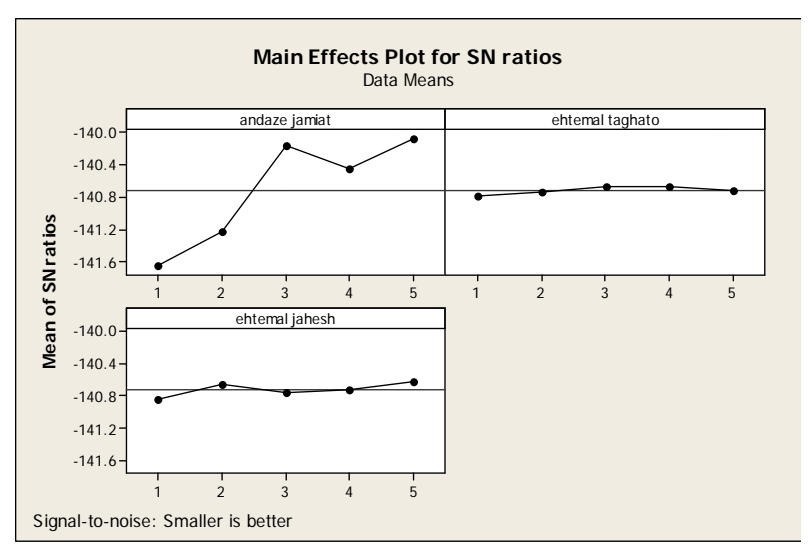

Fig. 4. The results of the main effects plot for $\mathrm{SN}$ ratios 
Table 2

Optimum levels of parameters in the suggested Genetic Algorithm

\begin{tabular}{llcc}
\hline Parameter & $\begin{array}{l}\text { Population size and The number of times } \\
\text { to repeat }\end{array}$ & Probability of crossover & Probability of mutation \\
\hline Optimum levels & $(60,180)$ & 0.9 & 0.09 \\
\hline
\end{tabular}

\section{Numerical illustration}

In order to present the implementation of the proposed study, we have examined the performance of the proposed study against some instances, which are randomly generated. In our survey, $\delta=0.9$, $\alpha=$ uniform $(0,1), \quad \mathrm{B}=$ uniform $(0,1), \quad \mathrm{CAP}=$ uniform $(20000,7000000)$ and $\mathrm{M}=$ uniform $(2000000,700000000)$ and other parameters are given in Table 3 as follows,

Table 3

Input Parameters

\begin{tabular}{llll}
\hline Parameter & Value & Parameter & Value \\
\hline TW(t) & uniform $(100,300)$ & CDQ $(\mathrm{i}, \mathrm{t})$ & uniform $(40,80)$ \\
WMAX(t) & uniform $(30,60)$ & CAQ $(\mathrm{i}, \mathrm{t})$ & uniform $(40,70)$ \\
TN(t) & uniform $(30,60)$ & $\mathrm{AN}(\mathrm{i}, \mathrm{t})$ & uniform $(100,300)$ \\
TA(t) & uniform $(100,300)$ & $\mathrm{V}(\mathrm{i}, \mathrm{t})$ & uniform $(20,40)$ \\
TM(i) & uniform $(80,200)$ & $\mathrm{CAO}(\mathrm{i}, \mathrm{t})$ & uniform $(40,70)$ \\
dn(i,k,t) & uniform $(40,80)$ & $\mathrm{CDO}(\mathrm{i}, \mathrm{t})$ & uniform $(40,80)$ \\
CG(t) & uniform $(40,80)$ & $\mathrm{CH}(\mathrm{t}, \mathrm{k})$ & uniform $(40,80)$ \\
MMAX(t) & uniform $(100000,400000)$ & $\mathrm{CLit}(\mathrm{i}, \mathrm{t})$ & uniform $(40,80)$ \\
TMT(t) & uniform $(100,300)$ & $\mathrm{CB}(\mathrm{i}, \mathrm{t})$ & uniform $(40,80)$ \\
VMAX $(\mathrm{t})$ & uniform $(100000,400000)$ & $\mathrm{CLtk}(\mathrm{t}, \mathrm{k})$ & uniform $(40,80)$ \\
R(i,t) & uniform $(100,300)$ & $\mathrm{CW}(\mathrm{t}, \mathrm{k})$ & uniform $(40,80)$ \\
D $(\mathrm{i}, \mathrm{t})$ & uniform $(100,1020)$ & $\mathrm{CFit}(\mathrm{i}, \mathrm{t})$ & uniform $(40,90)$ \\
\hline
\end{tabular}

We have solved the proposed method using GAMS 24.1.2 software to solve the problem to find the optimal solutions and the implementation of genetic algorithm has been coded in MATLAB. To compare the performance of genetic algorithm, we measure the relative gap between the solutions found by GAMS and MATLAB as follows,

Gap $=\frac{\mid \text { Opt.Solution }- \text { GASolution } \mid}{\text { Opt.Solution }} \times 100$

Table 4 shows the performance of the genetic algorithm versus the optimal solution found by GAMS software package. Fig. 5 also shows the schematic of the final solution for a small instance. As we can observe from the results of Table 4, the proposed study performs relatively well and the relative gap is small.

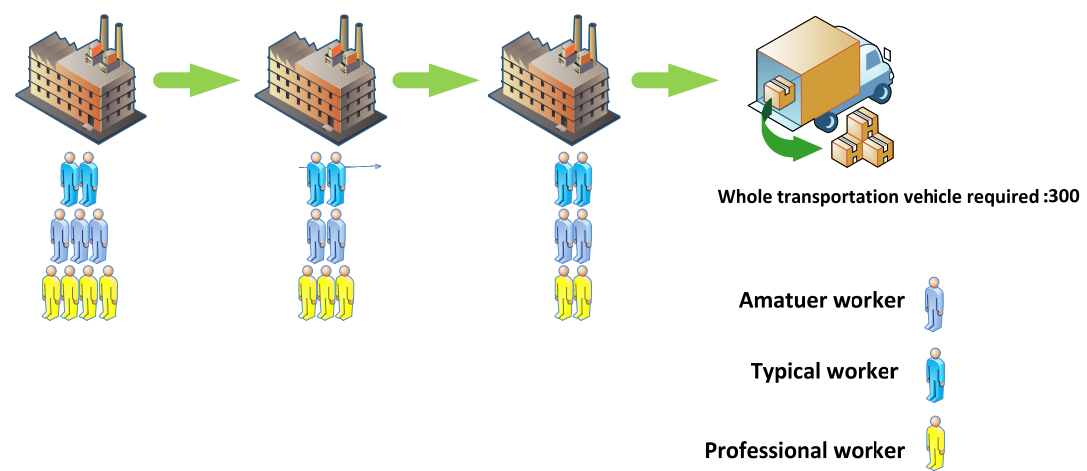

Fig. 5. Number of human resources and the carrying amount in Example 1 
Table 4

The performance of the genetic algorithm versus optimal solutions found using GAMS

\begin{tabular}{|c|c|c|c|c|c|c|}
\hline Example & $\begin{array}{l}\text { Parameter time \& } \\
\text { product }\end{array}$ & $\begin{array}{l}\text { Optimal value } \\
\text { in GAMS }\end{array}$ & $\begin{array}{l}\text { Solution time } \\
\text { in GAMS }\end{array}$ & $\begin{array}{c}\text { Optimal value in } \\
\text { Matlab }\end{array}$ & $\begin{array}{l}\text { Solution time in } \\
\text { Matlab }\end{array}$ & GAP \\
\hline 1 & $\mathrm{~N}=2 \mathrm{~T}=3$ & 151391 & 1.550 & 152140 & 16.8706 & $0.49 \%$ \\
\hline 2 & $\mathrm{~N}=5 \mathrm{~T}=5$ & 857190 & 1.960 & 867066 & 23.872 & $1.15 \%$ \\
\hline 3 & $\mathrm{~N}=7 \mathrm{~T}=7$ & 1635749 & 3.872 & 1640018 & 30.4209 & $0.26 \%$ \\
\hline 4 & $\mathrm{~N}=8 \mathrm{~T}=9$ & 2514706 & 4.321 & 2515830 & 37.3879 & $0.04 \%$ \\
\hline 5 & $\mathrm{~N}=10 \mathrm{~T}=14$ & 4660968 & 10.673 & 4694638 & 53.6199 & $0.72 \%$ \\
\hline 6 & $\mathrm{~N}=15 \mathrm{~T}=17$ & 8195010 & 21.012 & 8245099 & 73.506 & $0.61 \%$ \\
\hline 7 & $\mathrm{~N}=20 \mathrm{~T}=20$ & 13656650 & 28.454 & 13857057 & 99.3969 & $1.47 \%$ \\
\hline 8 & $\mathrm{~N}=8 \mathrm{~T}=16$ & 4182169 & 10.237 & 4208241 & 54.8465 & $0.62 \%$ \\
\hline 9 & $\mathrm{~N}=20 \mathrm{~T}=12$ & 7335630 & 12.923 & 7366067 & 64.7973 & $0.41 \%$ \\
\hline 10 & $\mathrm{~N}=2 \mathrm{~T}=15$ & 996181 & 2 & 1012012 & 38.7888 & $1.59 \%$ \\
\hline 11 & $\mathrm{~N}=30 \mathrm{~T}=25$ & 24940280 & 52.638 & 24967235 & 157.3603 & $0.10 \%$ \\
\hline 12 & $\mathrm{~N}=45 \mathrm{~T}=30$ & 46264200 & 113.362 & 46693968 & 252.9077 & $0.93 \%$ \\
\hline 13 & $\mathrm{~N}=55 \mathrm{~T}=60$ & 111792900 & 254.221 & 112694563 & 563.7762 & $0.82 \%$ \\
\hline 14 & $\mathrm{~N}=70 \mathrm{~T}=80$ & 191562400 & 320.122 & 192179207 & 928.83 & $0.32 \%$ \\
\hline 15 & $\mathrm{~N}=80 \mathrm{~T}=80$ & 213622000 & 490.954 & 216239819 & 1135.1201 & $1.22 \%$ \\
\hline 16 & $\mathrm{~N}=90 \mathrm{~T}=40$ & 122806600 & 271.771 & 123704839 & 568.9702 & $0.73 \%$ \\
\hline 17 & $\mathrm{~N}=40 \mathrm{~T}=60$ & 80036700 & 201.765 & 80654268 & 431.8726 & $0.77 \%$ \\
\hline 18 & $\mathrm{~N}=80 \mathrm{~T}=30$ & 81470520 & 209.432 & 81698001 & 436.5029 & $0.28 \%$ \\
\hline 19 & $\mathrm{~N}=25 \mathrm{~T}=80$ & 65026420 & 183.975 & 65672869 & 406.6816 & $0.99 \%$ \\
\hline 20 & $\mathrm{~N}=34 \mathrm{~T}=99$ & 113836500 & 259.621 & 114418622 & 652.5881 & $0.51 \%$ \\
\hline 21 & $\mathrm{~N}=100 \mathrm{~T}=100$ & 337589000 & 827.833 & 340456637 & 1652.503 & $0.85 \%$ \\
\hline 22 & $\mathrm{~N}=105 \mathrm{~T}=105$ & 368190200 & 856.211 & 371797750 & 1863.4288 & $0.98 \%$ \\
\hline 23 & $\mathrm{~N}=108 \mathrm{~T}=108$ & 392218900 & 884.754 & 394735250 & 1834.3239 & $0.64 \%$ \\
\hline 24 & $\mathrm{~N}=110 \mathrm{~T}=110$ & 419025100 & 904.865 & 420481118 & 2073.125 & $0.35 \%$ \\
\hline 25 & $\mathrm{~N}=112 \mathrm{~T}=112$ & 434237500 & 932.818 & 435225087 & 1911.3846 & $0.23 \%$ \\
\hline 26 & $\mathrm{~N}=115 \mathrm{~T}=115$ & - & ----- & 448729441 & 2019.4002 & ----- \\
\hline 27 & $\mathrm{~N}=120 \mathrm{~T}=120$ & - & ----- & 475692990 & 2337.3592 & ----- \\
\hline 28 & $\mathrm{~N}=125 \mathrm{~T}=125$ & - & ----- & 515309102 & 2671.2491 & ----- \\
\hline 29 & $\mathrm{~N}=130 \mathrm{~T}=130$ & - & ----- & 553782737 & 2965.3162 & ----- \\
\hline 30 & $\mathrm{~N}=140 \mathrm{~T}=140$ & - & ----- & 628168737 & 3583.9164 & ----- \\
\hline
\end{tabular}

\section{Conclusions}

In this study, a multi-product, multi-period and non-linear programming model has been presented for Production Planning problem where demand was under uncertainty. The primary goal was to propose a model for improvement of the production planning and minimization of the production system costs. The products in high volume and various types were produced and stored in bottles as the final products. For different production periods, the human forces capacities were considered and the level of employment or forces dismissal were considered. The production process was forwarding and backward process was not acceptable; that is, it was not allowable to rework in this system. Delivering final product from stockpiles to the retailers was also performed using vehicles with limited capacity. To solve the model in larger space and because of the complexity of the model, meta-heuristic algorithm is used. Finally, we have concluded that due to covering most of the assumptions in perishable products production, suggested model is closer to the real-world and reduce costs in production systems.

\section{Acknowledgement}

The authors would like to thank the anonymous referees for constructive comments on earlier version of this paper.

\section{References}

Abbasi, M., \& Houshmand, M. (2011). Production planning and performance optimization of reconfigurable manufacturing systems using genetic algorithm. The International Journal of Advanced Manufacturing Technology, 54(1-4), 373-392. 
Ahumada, O., \& Villalobos, J. R. (2011). Operational model for planning the harvest and distribution of perishable agricultural products. International Journal of Production Economics, 133(2), 677687.

Aung, M. M., \& Chang, Y. S. (2014). Temperature management for the quality assurance of a perishable food supply chain. Food Control, 40, 198-207.

Banerjee, P. K., \& Turner, T. R. (2012). A flexible model for the pricing of perishable assets. Omega, 40(5), 533-540.

Bilgen, B., \& Çelebi, Y. (2013). Integrated production scheduling and distribution planning in dairy supply chain by hybrid modelling. Annals of Operations Research, 211(1), 55-82.

Chen, K., \& Xiao, T. (2015). Production planning and backup sourcing strategy of a buyer-dominant supply chain with random yield and demand. International Journal of Systems Science, 46(15), 2799-2817.

Chen, H. K., Hsueh, C. F., \& Chang, M. S. (2009). Production scheduling and vehicle routing with time windows for perishable food products. Computers \& operations research, 36(7), 2311-2319.

Christou, I. T., Lagodimos, A. G., \& Lycopoulou, D. (2007). Hierarchical production planning for multi-product lines in the beverage industry. Production Planning \& Control, 18(5), 367-376.

Duong, L. N., Wood, L. C., \& Wang, W. Y. (2015). A multi-criteria inventory management system for perishable \& substitutable products. Procedia Manufacturing, 2, 66-76.

Farahani, P., Grunow, M., \& Günther, H. O. (2012). Integrated production and distribution planning for perishable food products. Flexible services and manufacturing journal, 24(1), 28-51.

Feng, L., Zhang, J., \& Tang, W. (2016). Optimal Inventory Control and pricing of Perishable items without shortages. IEEE Transactions on Automation Science and Engineering, 13(2), 918-931.

Gupta, M., \& Mohanty, B. K. (2015). Multi-stage multi-objective production planning using linguistic and numeric data-a fuzzy integer programming model. Computers \& Industrial Engineering, 87, 454-464.

Gyulai, D., Kádár, B., \& Monosotori, L. (2015). Robust production planning and capacity control for flexible assembly lines. IFAC-PapersOnLine, 48(3), 2312-2317.

Gramani, M. C. N., França, P. M., \& Arenales, M. N. (2011). A linear optimization approach to the combined production planning model. Journal of the Franklin Institute, 348(7), 1523-1536.

Hees, A., \& Reinhart, G. (2015). Approach for Production Planning in Reconfigurable Manufacturing Systems. Procedia CIRP, 33, 70-75.

Ji, Q., Wang, Y., \& Hu, X. (2016). Optimal production planning for assembly systems with uncertain capacities and random demand. European Journal of Operational Research, 253(2), 383-391.

Katsaliaki, K., Mustafee, N., \& Kumar, S. (2014). A game-based approach towards facilitating decision making for perishable products: An example of blood supply chain. Expert Systems with Applications, 41(9), 4043-4059.

Leung, S. C., \& Ng, W. L. (2007). A goal programming model for production planning of perishable products with postponement. Computers \& Industrial Engineering, 53(3), 531-541.

Mahmoodi, A., Haji, A., \& Haji, R. (2015). One for one period policy for perishable inventory. Computers \& Industrial Engineering, 79, 10-17.

Mirzaei, S., \& Seifi, A. (2015). Considering lost sale in inventory routing problems for perishable goods. Computers \& Industrial Engineering, 87, 213-227.

Mirzapour Al-E-Hashem, S. M. J., Aryanezhad, M. B., \& Sadjadi, S. J. (2012). An efficient algorithm to solve a multi-objective robust aggregate production planning in an uncertain environment. The International Journal of Advanced Manufacturing Technology, 58(5-8), 765-782.

Mirzapour Al-E-Hashem, S. M. J., Malekly, H., \& Aryanezhad, M. B. (2011). A multi-objective robust optimization model for multi-product multi-site aggregate production planning in a supply chain under uncertainty. International Journal of Production Economics, 134(1), 28-42.

Nguyen, C., Dessouky, M., \& Toriello, A. (2014). Consolidation strategies for the delivery of perishable products. Transportation Research Part E: Logistics and Transportation Review, 69, 108-121. 
Pauls-Worm, K. G., Hendrix, E. M., Alcoba, A. G., \& Haijema, R. (2015). Order quantities for perishable inventory control with non-stationary demand and a fill rate constraint. International Journal of Production Economics. 181, 238-246.

Pauls-Worm, K. G., Hendrix, E. M., Haijema, R., \& van der Vorst, J. G. (2014). An MILP approximation for ordering perishable products with non-stationary demand and service level constraints. International Journal of Production Economics, 157, 133-146.

Sel, C., Bilgen, B., Bloemhof-Ruwaard, J. M., \& van der Vorst, J. G. A. J. (2015). Multi-bucket optimization for integrated planning and scheduling in the perishable dairy supply chain. Computers \& Chemical Engineering, 77, 59-73.

Shah, N. K., \& Ierapetritou, M. G. (2012). Integrated production planning and scheduling optimization of multisite, multiproduct process industry. Computers \& Chemical Engineering, 37, 214-226.

Shen, Y. (2013). Multi-item production planning with stochastic demand: a ranking-based solution. International Journal of Production Research, 51(1), 138-153.

Shirvani, N., Ruiz, R., \& Shadrokh, S. (2014). Cyclic scheduling of perishable products in parallel machine with release dates, due dates and deadlines. International Journal of Production Economics, 156, 1-12.

Tarantilis, C. D., \& Kiranoudis, C. T. (2001). A meta-heuristic algorithm for the efficient distribution of perishable foods. Journal of food Engineering, 50(1), 1-9.

Zanjani, M. K., Ait-Kadi, D., \& Nourelfath, M. (2010). Robust production planning in a manufacturing environment with random yield: A case in sawmill production planning. European Journal of Operational Research, 201(3), 882-891.

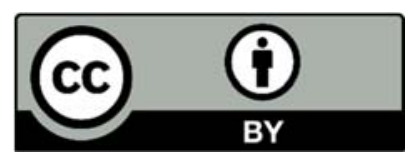

(C) 2017 by the authors; licensee Growing Science, Canada. This is an open access article distributed under the terms and conditions of the Creative Commons Attribution (CC-BY) license (http://creativecommons.org/licenses/by/4.0/). 